\title{
BIOCHEMICAL CHARACTERIZATION OF INSECTICIDE RESISTANCE IN INSECT PESTS OF VEGETABLES AND PREDATORY LADYBIRD BEETLES
}

\author{
B.T. DAMAYANTHI and S.H.P.P. KARUNARATNE* \\ Department of Zoology, University of Peradeniya, Peradeniya.
}

(Accepted: 19 May 2003)

\begin{abstract}
Insecticide resistance and the underlying resistance mechanisms were studied in seven species of insect vegetable pests (aphids Aphis gossypii, Myzus persicae, Aphis craccivora, Toxoptera citricidus and Lipaphis erysimi; diamond-back-moth Plutella xylostella; leafminer Liriomyza huidobrensis) and two predatory ladybird beetles (Coccinella sexmaculatus and Thea cincta). Insects, collected from the Central Province, Sri Lanka were subjected to bioassays with malathion, chlorpyrifos, propoxur and permethrin by topical application and $\mathrm{LC}_{50}$ and $\mathrm{LC}_{90}$ values were obtained. $M$. persicae, $P$. xylostella and $L$. huidobrensis had high resistance to all the insecticides tested with the exception of $M$. persicae to propoxur. The aphid $T$. citricidus was the least tolerant pest to all four insecticides tested. Compared to the pest species, the ladybird beetle $C$. sexmaculatus had a moderate level of insecticide tolerance whereas $T$. cincta was more susceptible. DDT resistance, as determined by a discriminating concentration, was highest in P. xylostella and least in L. huidobrensis.
\end{abstract}

Biochemical analysis of insect metabolic enzymes showed that elevation of esterases was the major resistance mechanism in aphids and $P$. xylostella. Highest esterase activity was present in $M$. persicae. Native polyacrylamide gel electrophoresis resolved elevated esterase isoenzymes in all species except in $T$. citricidus and T. cincta. Malathion carboxylesterase activity was found in $P$. xylostella, $M$. persicae, and $L$. huidobrensis. Higher glutathione S-transferase activities of $P$. xylostella and $L$, erysim $i$ were correlated with their higher DDT resistance. Increased mono-oxygenase titres occurred in $A$. gossypii, $M$. persicae and T. citricidus. Insecticide inhibition of the organophosphate and carbamate target site acetylcholinesterases indicated that target site insensitivity is a major mechanism in L. huidobrensis.

Keywords: insecticide resistance, predatory insects, vegetable insect pests.

\section{INTRODUCTION}

Insect pests are a serious problem in tropical agriculture. Extensive use of insecticides has been the major method of insect pest control in Sri Lanka for more than five decades. After DDT use was banned in 1977, malathion was used for residual house spraying in malaria control programmes, while carbamates were used extensively in agriculture. Pyrethroids were introduced in mid 1990s into both agriculture and health sectors. Extensive use of insecticides has selected many insecticide resistant insect populations causing a severe problem in pest management programmes of the country. Although there are rich communities of insect predatory species that reduce pest populations, the use of insecticides affects both predators and pests. It is important to identify the insecticide cross-resistance spectra and the underlying resistance mechanisms of both pest and predatory insect populations to rationally select suitable insecticide groups which maximise pest control and minimise the effect on their natural enemies. We report here the resistance status of seven important vegetable insect pest species against organochlorines (DDT), organophosphates (malathion, chlorpyrifos), carbamates (propoxur) and pyrethroids (permethrin). Two species of ladybird beetles were also used to determine the resistance status of predatory species in relation to their prey species.

Resistance to insecticides mainly occurs due to changes in insect metabolic enzymes or due to the development of insecticide insensitive target sites in the insect nervous system ${ }^{1}$. Increased metabolism is often caused by qualitative and/or quantitative changes of esterases, glutathione S-transferases and monooxygenases. Target site insensitivity is often caused by highly specific point mutations. Mutated target sites do not bind to insecticides but perform their normal physiological functions. Prevalence of these resistance mechanisms in the above mentioned insect populations were also monitored.

\section{METHODS AND MATERIALS}

Insects: Five species of apterous adult aphids (Homoptera: Aphididae) ie. Aphis gossypii, Myzus persicae, Aphis craccivora, Toxoptera citricidus 
and Lipaphis erysimi; adult diamondback moth Plutella xylostella (Lepidoptera: Yponomeutidae); and the adult ladybird beetles (Coleoptera: Coccinellidae) Coccinella sexmaculatus and Thea cincta were collected from agricultural crops in Kandy region. Adult leafminer Liriomyza huidobrensis (Diptera: Agromizidae) were collected from Nuwara Eliya area. Insects were directly used for bioassays or frozen at $-20^{\circ} \mathrm{C}$. Frozen insects were used for biochemical assays within 2 wk.

Chemicals and equipment: Chemicals were purchased from Sigma, U.K., unless otherwise stated. DDT (97.5\% pure) and paraoxon (98\% pure) were from Greyhound, UK. Malathion (97.5\% pure) and chlorpyrifos (98\% pure) were a gift from Cheminova, Denmark. Propoxur (98.5\% pure) was from Bayer, Germany and permethrin (98\% pure) was from Aventis, UK. The protein assay kit and mini-protean II electrophoresis kit were from BioRad, UK.

Insect bioassays: Bioassays for malathion, chlorpyrifos, propoxur, permethrin and DDT were undertaken by topical application. Insecticide stock solutions were prepared in acetone. Dilutions were made with $70 \%$ ethanol. Final working solutions always had an acetone concentration of $<0.01 \%$. Insecticide solution $(0.25 \mu \mathrm{l}$ per $0.25 \mu \mathrm{g}$ insect wet body weight) was applied to the thorax of each insect using a Burcard topical applicator and the mortalities were recorded after $24 \mathrm{~h}^{2}$ At least five concentrations of each insecticide (except DDT), giving mortalities between $0-100 \%$ were used for each species. A minimum of 100 insects per concentration per species was tested. Controls were treated with solvent alone. Results were used only if the mortalities in the controls were $<20 \%$. Control mortalities were adjusted for using Abbott's formula. ${ }^{3}$ Mortalities were plotted against insecticide concentrations to obtain logconcentration probit-mortality lines and $\mathrm{LC}_{50}$ and $\mathrm{LC}_{90}$ values were calculated by regression analysis. DDT bioassays were carried out by applying a discriminating concentration (determined by preliminary experiments) of $1.4 \mu \mathrm{g} / \mathrm{mg}$ wet body weight.

Biochemical assays with individual insects: Adult insects were individually subjected to esterase, glutathione S-transferase (GST), mono-oxygenase and protein assays using a kinetic microtitre plate reader (Bio-Tek, USA) at $22{ }^{\circ} \mathrm{C}$. At least 200 individuals from each population were tested. Each insect was homogenised in $150 \mu \mathrm{l}$ of distilled water and centrifuged at $10,000 \mathrm{~g}$ for $2 \mathrm{~min}$. Supernatants were tested individually for the enzyme activities in microtitre plates.

Esterase assay: Homogenate ( $10 \mu \mathrm{l})$ was mixed with $200 \mu \mathrm{l}$ of $1 \mathrm{mM} p$-nitrophenyl acetate (pNPA) in 50 $\mathrm{mM}$ sodium phosphate buffer ( $\mathrm{pH} 7.4$ ). The increase in absorbance was monitored at $405 \mathrm{~nm}$ for $2 \mathrm{~min}$. An extinction co-efficient of $6.53 \mathrm{mM}^{-1}$ (corrected for a path length of $0.6 \mathrm{~cm}$ ) was used to convert the absorbance to moles. ${ }^{4,5}$

Glutathion S-transferase assay: Homogenate $(10 \mu \mathrm{l})$ was mixed with $200 \mu$ l of substrate solution [95 parts of $10.5 \mathrm{mM}$ reduced glutathione in $100 \mathrm{mM}$ phosphate buffer +5 parts of $63 \mathrm{mM} 1$-chloro 2,4dinitrobenzene (CDNB) in methanol]. The rate of reaction was measured at $340 \mathrm{~nm}$ for $5 \mathrm{~min}$. An extinction co-efficient of 5.76 (corrected for path length of $0.6 \mathrm{~cm}$ ) was used to convert absorbance to moles. ${ }^{6}$

Mono-oxygenase assay: Homogenate $(20 \mu \mathrm{l})$ was mixed with $80 \mu \mathrm{l}$ of potassium phosphate buffer $(\mathrm{pH} 7.2)+200 \mu \mathrm{l}$ of $6.3 \mathrm{mM}$ tetramethyl benzidine (TMBZ) working solution (0.01g TMBZ dissolved in $5 \mathrm{ml}$ methanol and then in $15 \mathrm{ml}$ of sodium acetate buffer $\mathrm{pH} 5.0)+25 \mu \mathrm{l}$ of $3 \% \mathrm{H}_{2} \mathrm{O}_{2}$ solution in a microtitre plate well. After $2 \mathrm{~h}$ incubation at room temperature, the plate was read at $630 \mathrm{~nm}$ as an end point assay. ${ }^{7}$ This assay does not measure mono-oxygenase activity but titrates the amount of bound haem in the insect homogenate. Since haem is present in the active site of monooxygenase and is the major haem component in insects, the amount of haem corresponds to the amount of mono-oxygenase present. By using a standard curve of pure cytochrome $\mathrm{C}$, which contains one bound haem per molecule, an estimate of the amount of mono-oxygenases present was obtained and expressed as equivalent units of cytochrome $\mathrm{P}^{450}$ ?

Protein assay: To obtain specific activities of the enzymes, protein concentrations of the homogenates were determined using a BIO-RAD protein determination kit, with bovine serum albumin as the standard protein. ${ }^{8}$ Homogenate $(10 \mu \mathrm{l})$ was 
mixed with $300 \mu \mathrm{l}$ of working solution (prepared according to the manufacturer's instructions). After incubation at $22^{\circ} \mathrm{C}$ for $5 \mathrm{~min}$, the absorbance was read at $570 \mathrm{~nm}$ as an endpoint assay.

Malathion metabolism (malathion carboxylesterase assay): Batches of 5-80 individuals (equivalent to $10 \mathrm{mg}$ wet weight) of each insect species were homogenized in $0.5 \mathrm{ml}$ of $25 \mathrm{mM}$ Tris-HCl buffer $(\mathrm{pH} 7.5)$ and centrifuged at $13,000 \mathrm{~g}$ for $5 \mathrm{~min}$. Supernatant was incubated with $300 \mu \mathrm{M}$ malathion for $2 \mathrm{~h}$ at $28^{\circ} \mathrm{C}$. The mixture was then extracted twice with $0.5 \mathrm{ml}$ acidified chloroform. The chloroform extract was dried under a current of air, redissolved in $30 \mu$ ] acidified chloroform and loaded onto a thin layer chromatography plate. After running with a mobile phase of $n$-hexane: diethyl ether (1:3) the plate was sprayed with $0.5 \%(\mathrm{w} / \mathrm{v}) 2,6$ dibromoquinone 4-chloromide in cyclohexane and left at $100^{\circ} \mathrm{C}$ for $2 \mathrm{~h}$ to visualise malathion and its metabolites. Buffer $(0.5 \mathrm{ml})$ incubated with $300 \mu \mathrm{M}$ malathion and $300 \mu \mathrm{M} \mathrm{NaOH}$ was run as a positive control. Buffer, incubated with the same concentration of malathion, was run as a negative control. Fast metabolism of malathion is considered to be due to qualitatively different malathion carboxylesterases (MCEs). This assay was used to determine the presence of MCE mechanism. ${ }^{9}$

Gel electrophoresis: Native polyacrylamide gel electrophoresis (PAGE) was used to visualise elevated esterase isoenzymes. Mass homogenates of 20-150 individuals (equivalent to $25 \mathrm{mg}$ wet weight) of each insect species were homogenized in $250 \mu \mathrm{l}$ of $50 \mathrm{mM}$ sodium phosphate buffer $\mathrm{pH}$ 7.4. Electrophoresis of $10,000 \mathrm{~g}$ supernatants from crude homogenates was performed in $7.5 \%$ acrylamide gels in tris/borate buffer $\mathrm{pH} 8.0$ containing $0.2 \mathrm{mM}$ EDTA. Gels were stained for esterase activity with $0.04 \%(\mathrm{w} / \mathrm{v}) \alpha$ - and $\beta$ naphthyl acetate and $0.1 \%(\mathrm{w} / \mathrm{v})$ fast blue $\mathrm{B}$ in $100 \mathrm{mM}$ phosphate buffer $\mathrm{pH}$ 7.4. Nilaparvata lugens with elevated esterases were used as a positive control..$^{10}$ For inhibition studies, gels were pre-incubated, after electrophoresis, in $0.1 \mathrm{mM}$ paraoxon, propoxur or permethrin in $50 \mathrm{mM}$ phosphate buffer $\mathrm{pH} 7.4$ for $15 \mathrm{~min}$, and then stained for esterase activity as above in the presence of the insecticide.

Bimolecular rate constant $k_{i}$ for AChE inhibition: Mass crude homogenates (100 mg wet weight) in
$300 \mu \mathrm{l}$ of $50 \mathrm{mM}$ phosphate buffer $\mathrm{pH} 7.4$ were prepared. Supernatant $(250 \mu \mathrm{l})$ was incubated with $100 \mu \mathrm{M}$ propoxur. Aliquots $(20 \mu \mathrm{l})$ were withdrawn at $10 \mathrm{~s}$ intervals and mixed with an excess of acetylthiocholine iodide (ASCHI) and 5,5, dithiobis-(2-nitrobenzoic acid) (DTNB) in $100 \mathrm{mM}$ phosphate buffer pH 7.8 and 1\% Triton X-100. Residual AChE activity was measured at $405 \mathrm{~nm}$ for $5 \mathrm{~min}$. Uninhibited homogenate was assayed as a control. Log \% remaining activity in the propoxur inhibited aliquot compared to the control was plotted against time, and the bimolecular rate constant $k_{\mathrm{i}}$ for AChE inhibition was calculated. ${ }^{11}$

\section{RESULTS}

Calculated $\mathrm{LC}_{50}$ and $\mathrm{LC}_{90}$ values for malathion, chlorpyrifos, propoxur and permethrin for all the insect species are given in the Table 1 . Of the pest species, $M$. persicae, $P$. xylostella and $L$. huidobrensis had higher levels of resistance to all the insecticides tested, with the exception of $M$. persicae to propoxur. A. gossipi showed a high resistance to propoxur. The aphid $T$. citricidus was the least tolerant to all four insecticides. Although the ladybird beetle $C$. sexmaculatus had a moderate level of resistance to chlorpyrifos and high resistance to propoxur, its permethrin tolerance was low. Tolerance of $T$. cincta to all insecticides was very low. Heterogeneity of response to insecticide exposure is shown by the $\chi^{2}$ values of the mortality curves and seen in $M$. persicae population for malathion and in $A$. craccivora and C. sexmaculatus populations for permethrin (Table 1). Mortalities for DDT at the fixed dosage of $1.4 \mu \mathrm{g} / \mathrm{mg}$ wet body weight were L. huidobrensis (92\%), T. citricidus (63\%), $M$. persicae (44\%), A. gossypii (38\%), A. craccivora (27\%), C. sexmaculatus (20\%), T. cincta (17\%), L. erysimi (16\%) and P. xylostella (13\%).

A minimum of 200 insects from each species were tested individually for the activities of esterases and glutathione S-transferases and estimates of mono-oxygenase content. Means \pm standard deviations obtained from 27 enzyme \% activity frequency distribution patterns are presented in Table 2. High standard deviations indicate the heterogeneity among the individuals of each population. Increased esterase activities were observed in $M$. persicae, A. gossypii and $L$. erysimi. All species, except the aphid $T$. citricidus 


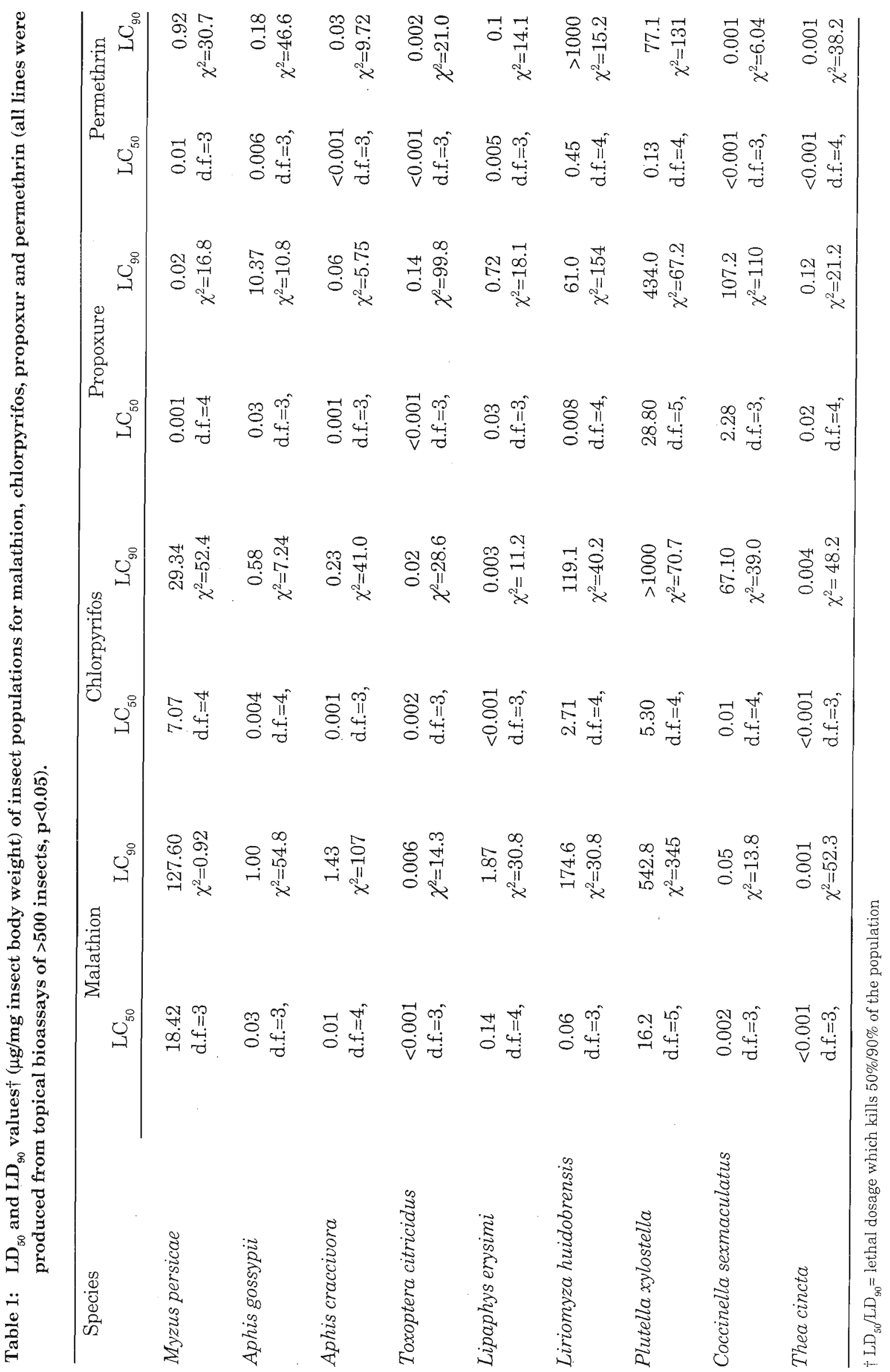


Table 2: Mean values \pm standard deviation of specific activities of esterases and glutathione Stransferases and estimates of mono-oxygenase content in different insect populations.

\begin{tabular}{lccc}
\hline Insect Species & $\begin{array}{c}\text { esterase } \\
\text { specificactivity } \\
(\mu \mathrm{mol} / \mathrm{min} / \mathrm{mg})\end{array}$ & $\begin{array}{c}\text { GST } \dagger(\mu \mathrm{mol} / \mathrm{min} / \mathrm{mg}) \\
\text { specific activity } \\
(\mu \mathrm{mol} / \mathrm{min} / \mathrm{mg})\end{array}$ & $\begin{array}{c}\text { mono-oxygenase } \\
\text { estimation* }\end{array}$ \\
\cline { 2 - 4 } Myzus persicae & $1.006 \pm 0.64$ & $0.636 \pm 0.62$ & $13.89 \pm 16.38$ \\
Aphis gossypii & $0.71 \pm 0.54$ & $0.82 \pm 0.59$ & $67.81 \pm 78.9$ \\
Aphis craccivora & $0.23 \pm 0.20$ & $0.50 \pm 0.33$ & $10.33 \pm 12.8$ \\
Toxoptera citricidus & $0.16 \pm 0.20$ & $0.62 \pm 0.53$ & $26.71 \pm 34.3$ \\
Lipaphis erysimi & $0.56 \pm 0.50$ & $1.34 \pm 0.93$ & $6.66 \pm 58.1$ \\
Liriomyza huidobrensis & $0.14 \pm 0.20$ & $0.39 \pm 0.27$ & $1.08 \pm 1.75$ \\
Plutella xylostella & $0.25 \pm 0.16$ & $1.43 \pm 1.24$ & $3.21 \pm 3.91$ \\
Thea cincta & $0.20 \pm 0.15$ & $0.60 \pm 0.54$ & $4.78 \pm 5.50$ \\
Coccinella sexmaculatus & $0.31 \pm 0.12$ & $0.75 \pm 0.28$ & $1.27 \pm 0.98$ \\
\hline
\end{tabular}

$\dagger$ glutathione S-transferase $\quad *$ equivalent units of cytochrome $\mathrm{P}^{450}$

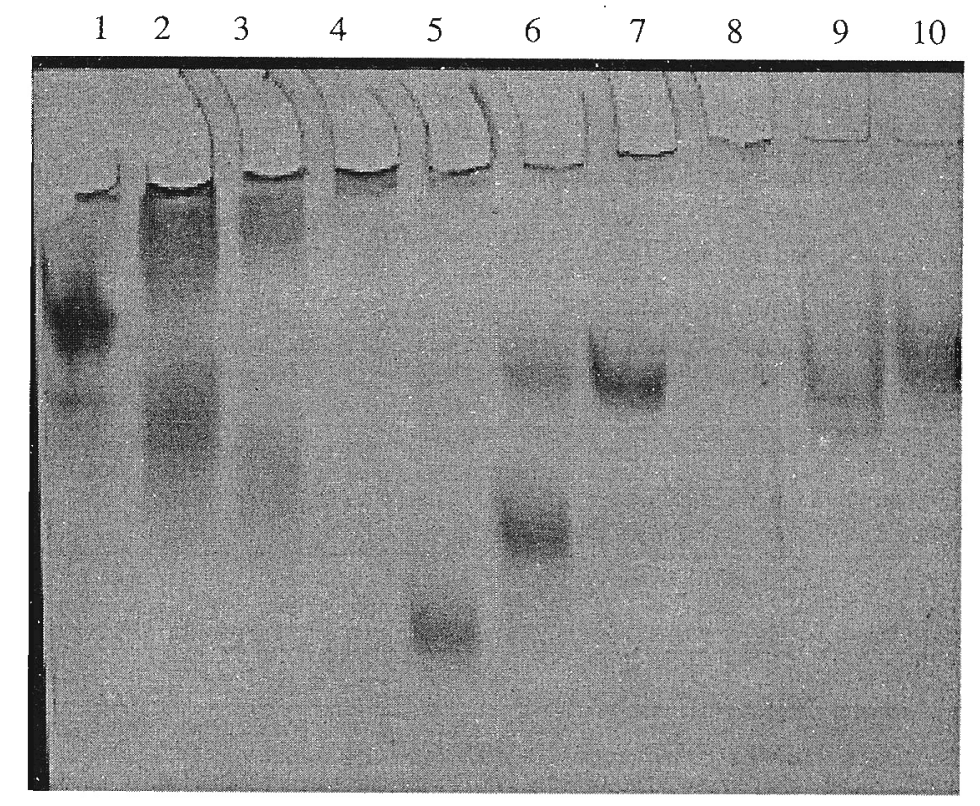

Figure 1: Native polyacrylamide gel electrophoresis of elevated esterases from crude homogenates of insect species. Esterase pattern from Nilaparvata lugens is present as a positive control. Lane: 1. Myzus persicae, 2. Aphis gossypii, 3. Aphis craccivora, 4. Toxoptera citridus, 5. Lipaphis erysimi, 6. Plutella xylostella, 7. Liriomyza huidobrensis, 8. Thea cincta, 9. Coccinella sexamaculatus, 10. Nilaparvata lugens

and the ladybird beetle $T$. cincta, had elevated esterase bands on native polyacrylamide gels (Figure 1). The amount of protein per well in each electrophoresis experiment was set so that non- elevated esterase bands would be below the limits of detection. ${ }^{12}$ Elevated esterase bands were completely inhibited by $0.1 \mathrm{mM}$ paraoxon, partially inhibited by $0.1 \mathrm{mM}$ propoxur and not inhibited by 
$0.1 \mathrm{mM}$ permethrin except the slowest running band of $M$. persicae, which was not inhibited by any of the insecticides tested. Malathion carboxylesterase activity was found only in $M$. persicae, $P$. xylostella and $L$. huidobrensis, all of which had high levels of resistance to malathion. Crude homogenates of these three species metabolised malathion into both its mono- and di-acid products after 2 hours incubation (Figure 2). Ladybird beetle species, which had a low level of tolerance to malathion did not have malathion carboxylesterase activities (results not shown). Higher DDT resistance, shown by $P$. xylostella and $L$. erysimi populations, was correlated with their elevated GST activity levels (Table 2). Involvement of mono-oxygenases in the insecticide resistance of these insect species was indirectly tested by quantifying bound haem. ${ }^{7} A$. gossypii, $M$. persicae and $A$. craccivora had the highest mono-oxygenase estimates (Table 2). Lower mono-oxygenase content was estimated in L. huidobrensis and C. sexmaculatus. Bimolecular rate constants for the inhibition of AChEs with propoxur are given in Table 3. AChEs are the target site of organophosphorous and carbamate insecticides. L. huidobrensis AChEs had the lowest inhibition rate suggesting a high frequency of insensitive $\mathrm{AChE}$ alleles in the lexfminer population.
Table 3: Bimolecular rate constants $\left(k_{i} s\right)$ for acetylcholinesterase-propoxur (1mM) inhibition reactions.

\begin{tabular}{lc}
\hline Insect species & $\mathbf{k}_{\mathbf{i}}\left(\mathbf{M}^{-\mathbf{1}} \mathbf{m i n}^{-1} \times \mathbf{1 0}^{\mathbf{4}}\right)$ \\
\hline Myzus persicae & 0.456 \\
Aphis gossypii & 1.161 \\
Aphis craccivora & 0.497 \\
Toxoptera citricidus & 0.345 \\
Lipaphis erysimi & 0.705 \\
Liriomyza huidobrensis & 0.138 \\
Plutella xylostella & 0.415 \\
Coccinella sexmaculatus & 0.801 \\
Thea cincta & 0.338 \\
\hline
\end{tabular}

\section{DISCUSSION}

Compared to the pest specie, the predatory ladybird beetle $C$. sexmaculatus had a moderate level of insecticide tolerance whereas $T$. cincta was more susceptible. Similar levels of insecticide tolerance between aphids and ladybird beetles, have been reported previously as well. ${ }^{13}$

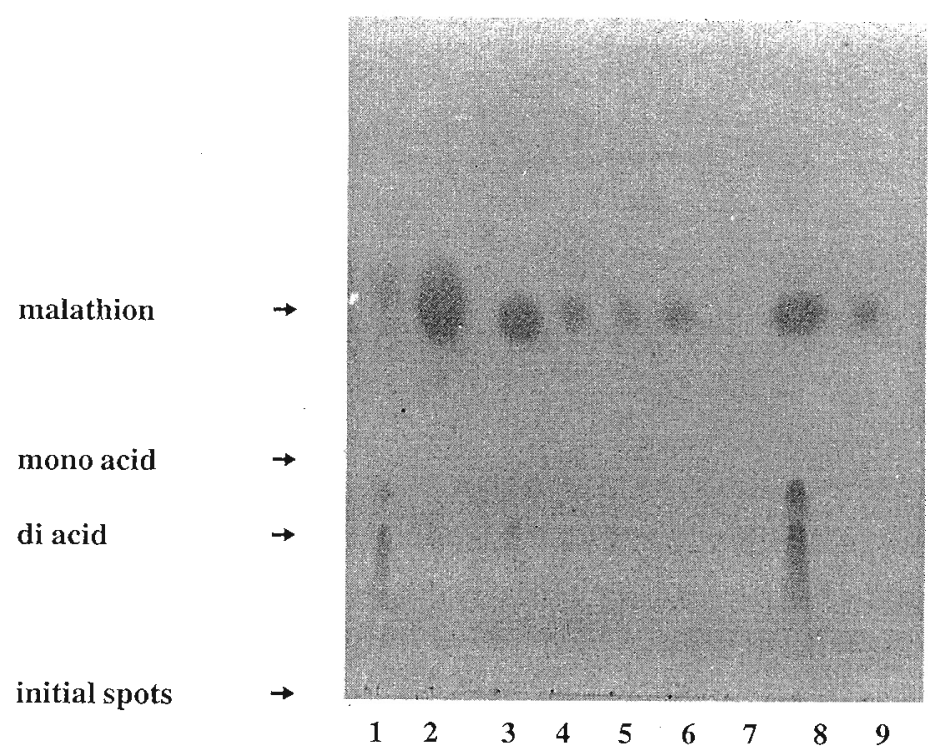

Figure 2: Thin layer chromatography of insect pest homogenates incubated with malathion. $\mathrm{NaOH}$ and the homogenisation buffer were incubated with malathion as positive and negative controls respectively.

Lane: 1. Plutella xylostella, 2. Liriomyza huidobrensis, 3. Myzus persicae, 4. Lipaphis erysimi, 5. Aphis craccivora, 6. Aphis gossypii, 7. Toxoptera citridus, 8. positive control. 9. negative control 
In Sri Lanka, the organochlorines DDT and $\gamma$-BHC were used extensively in agriculture until the mid 1970s. Organophosphates were introduced in the 1960s but the use of malathion and fenitrothion in agriculture was legally restricted because of their important role in malaria control. Carbamates were the major group of insecticides used in agriculture until the introduction of pyrethroids in the mid 1990s. The present study shows that both the agricultural insect pests and their natural enemies in Sri Lanka have evolved different insecticide tolerance patterns over the last five decades. The major resistance mechanism in the aphids and in the diamondback moth $P$. xylostella was elevated esterases. It has been reported that aphids and Culex mosquitoes confer organophosphate and carbamate resistance primarily through esterases. ${ }^{12,} 14,15$ The aphid E4 esterase also hydrolyses permethrin, ${ }^{16}$ while the mosquito esterases are unable to interact with this either as a substrate or as an inhibitor. ${ }^{5,12}$ In the present study, the inhibition of elevated esterase bands by paraoxon and propoxur confirms that these esterases confer organophosphorous and carbamate insecticide resistance. The results also suggest that they are not reactive with permethrin. Extensive use of malathion in malaria control activities in Sri Lanka has contributed to the pressure for the selection of malathion carboxylesterase mechanism in several malaria vector populations. ${ }^{9}$ Exposure of agricultural insects to malathion sprayings and the illegal use of malathion for agricultural purposes may have selected malathion carboxylesterase mechanism in some of the agricultural insects as well. Some of the tested populations had a very high DDT tolerance, despite 20 years without DDT use. GSTs are known as DDT hydrochlorinases because of their active role in DDT metabolism. ${ }^{17}$ DDT tolerance seen in the tested populations was well correlated with their GST activity levels. Mean specific GST activities in some species were higher than those of Sri Lankan malaria vectors Anopheles culicifacies and A. subpictus. ${ }^{18} \mathrm{It}$ is possible that the DDT resistance has been maintained even after the cessation of DDT, through GST's which act as a secondary source of organophosphate or pyrethroid resistance. ${ }^{19,} 20$ Increased metabolism by esterases and GSTs has been identified as a major mechanism in the storage pest of legumes, Callosobruchus maculates. ${ }^{21}$ Mono-oxygenases can produce high levels of resistance to pyrethroids. However, the high pyrethroid resistance shown by $P$. xylostella with low mono-oxygenase estimates, may be due to the activity of other metabolic enzymes and/or altered pyrethroid target sites or a quantitative change in one or more mono-oxygenases which does not affect gross enzyme titres.

L. huidobrensis is a recently introduced insect pest in Sri Lanka. It caused a 95\% loss of potato yield and a severe loss of beetroot and leek yields in NuwaraEliya area in 1997. Control of this pest was not easy due to its high resistance to the recommended insecticides. The present study shows that Nuwara Eliya L. huidobrensis population is highly resistant to organophosphates, carbamates and pyrethroids but susceptible to DDT. As it is evident from the present results, high resistance of this population to other groups of insecticides is probably due to the presence of insensitive insecticide target sites.

\section{Acknowledgement}

We thank Dr. Mangalika Nugaliyadda and Dr. Rohini Ekanayake, Department of Agriculture, for their assistance in the field. Financial assistance was given by the Postgraduate Institute of Science, University of Peradeniya.

\section{References}

1. Karunaratne S.H.P.P. (1998). Insecticide resistance in insects: A review. Ceylon Journal of Science (Biological Sciences) 25: 72-79.

2. Beranek A.P. (1974). Esterase variation and organophosphate resistance in populations of Aphis fabae and Myzus persicae. Entomologia Experimentalis Applicata 17: 129-142.

3. Matsumara F. (1985). Toxicology of Insects. 598 pp. Plenum press, New York.

4. Dary O., Georghiou G.P., Parsons E. \& Pasteur N. (1990). Microplate adaptation of Gomaris assay for quantitative determination of general esterase activity in single insects. Journal of Economic Entomology 83: 2187-2192.

5. Karunaratne S.H.P.P., Jayawardena K.G.I., Hemingway J. \& Ketterman A.J. (1993). Characterization of a $\beta$-type esterase involved 
in insecticide resistance from the mosquito Culex quinquefasciatus. Biochemical Journal 294: 575579 .

6. Brogdon W.G. \& Barber A.M. (1990). Microplate assay of glutathione S-transferase activity for resistance detection in single mosquito triturates. Comparative Biochemistry and Physiology 96: 339-342.

7. Brogdon W.G., McAllister J.C. \& Vulule J.M. (1997). Heam peroxidase activity measured in single mosquitoes identifies individuals expressing an elevated oxidase for insecticide resistance. Journal of American Mosquito Association 13: 233.

8. Bradford M.M. (1976). A rapid and sensitive method for quantification of microgram quantities of protein utilizing the principles of protein-dye binding. Analytical Biochemistry 72: 248-254.

9. Karunaratne S.H.P.P. \& Hemingway J. (2001). Malathion resistance and prevalence of the malathion carboxylesterase mechanism in populations of mosquito vectors of disease in Sri Lanka. Bulletin of the World Health Organization 79: 1060-1064.

10. Hemingway J., Karunaratne S.H.P.P. \& Claridge M.F. (1999). Insecticide resistance spectrum and underlying resistance mechanisms in tropical populations of the brown planthopper (Nilaparvata lugens) collected from rice and the wild grass Leersia hexandra. International Journal of Pest Management 45: 215-223.

11. Karunaratne S.H.P.P. \& Hemingway J. (1996). Different insecticides select multiple carboxylic isoenzymes and different resistance levels from a single population of Culex quinquefasciatus. Pesticide Biochemistry and Physiology 54: 4-11.

12. Karunaratne S.H.P.P., Hemingway J., Jayawardena K.G.I., Dassanayaka V. \& Vaughan A: (1995). Kinetic and molecular differences in the amplified and non amplified esterases from insecticide resistant and susceptible Culex quinquefasciatus mosquitoes. The Journal of Biological Chemistry 270(52): 31124-31128.
13. Wiles J.A. \& Jepson P.C. (1992). The susceptibility of a cereal aphid pest and its natural enemies to deltamethrin. Pesticide Science 36: 263-272.

14. Devonshire A.L. (1977). The properties of a carboxylesterase from the peach-potato aphid Myzus persicae (Sulz.), and its role in conferring insecticide resistance. Biochemical Journal 167 : 675-683.

15. Karunaratne S.H.P.P. \& Hemingway J. (2000). Insecticide resistance spectra and the underlying resistance mechanisms in populations of Japanese encephalitis vector mosquitoes, Culex tritaeniorhynchus and C. gelidus, from Sri Lanka. Medical and Veterinary Entomology 14: 1-7.

16. Devonshire A.L. \& Moores G.D. (1982). A carboxylesterase with broad substrate specificity causes organophosphorus, carbamate and pyrethroid resistance in peach-potato aphids (Myzus persicae). Pesticide Biochemistry and Physiology 18: 235-246.

17. Clark A.G. \& Shamaan N.A. (1984). Evidence that DDT-hydrochlorinase from the housefly is a glutathione S-transferase. Pesticide Biochemistry and Physiology 22: 249-261.

18. Karunaratne S.H.P.P. (1999). Insecticide crossresistance spectra and underlying resistance mechanisms of Sri Lankan anopheline vectors of malaria. Southeast Asian Journal of Tropical Medicine and Health 30: 460-469.

19. Hemingway J., Miyamoto J. \& Herath P.R.J. (1991). A possible novel link between organophosphorous and DDT insecticide resistance genes in Anopheles: supporting evidence from fenitrothion metabolism studies. Pesticide Biochemistry and Physiology 39: 49-56.

20. Vontas J.G., Small G.J., \& Hemingway J. (2001). Glutathion S-transferase as antioxidant defence agents confer pyrethroid resistance in Nilaparvata lugens. Biochemical Journal 357: 65-72.

21. Bogamuwa M.M.S., Weerakoon K.C. \& Karunaratne S.H.P.P. (2002). Insecticide resistance in the bruchid Callosobruchus maculates, a storage pest of legumes. Ceylon Journal of Science (Biological Sciences) 30:5566. 